\title{
Systematic review of factors associated with quality of life of asylum seekers and refugees in high-income countries
}

\author{
Catharina F. van der Boor ${ }^{1}$, Rebekah Amos' ${ }^{1}$ Sarah Nevitt ${ }^{2}$, Christopher Dowrick ${ }^{1}$ and Ross G. White ${ }^{1,3^{*}}$ (D)
}

\begin{abstract}
The stressful experiences that many asylum seekers and refugees (AS\&R) are exposed to during forced migration, and during resettlement in host countries, can have a profound impact on their mental health. Comparatively less research attention has been allocated to exploring other indices of quality of life (QoL) in AS\&R populations. This review aimed to (i) synthesize the predictors and correlates of QoL of AS\&R populations in high-income countries, and (ii) to identify the methodological strengths and weaknesses of this body of research.

Fourteen databases were systematically searched (Medline, PsychINFO, CINAHL, Cochrane Library, Health Technology Assessment, National Health Service Economic Evaluation, Educational Resource Index and Abstracts, BiblioMap, Scopus, Social Sciences Citation Index, Evidence Aid, DARE, Web of Science and PubMed). Eligibility criteria included: adults seeking asylum or refuge in a high-income country, primary quantitative data, the use of a measure based on the WHO's definition of QoL, published in a peer-reviewed journal. A narrative synthesis approach was used, and the quality was assessed using the AXIS tool for cross-sectional studies and the CASP tool for longitudinal studies.

Of the 13.656 papers identified, 23 met the eligibility criteria. A wide range of factors were found to have significant associations with QoL. Both positive and negative correlates of QoL were largely dominated by social (e.g. social networks) and mental health factors (e.g. depression). Although all of the cross-sectional studies met over half of the quality criteria, only 12 met $75 \%$ or more of these criteria. For the longitudinal studies, for all but one study lacked statistical precision and the results cannot be applied to the local population.

Key findings across the various forms of QoL (overall, physical, psychological, social and environmental) were that having established social networks and social integration were associated with higher QoL, whereas having mental disorders (i.e. PTSD or depression) was strongly associated with reduced QoL. More research is needed into physical and environmental predictors and correlates of QoL. The findings of the review can be used to inform policies and interventions aimed at supporting AS\&R and promoting the integration and wellbeing of these populations.
\end{abstract}

Keywords: Quality of life, Asylum seekers, Refugees, Migration

\footnotetext{
* Correspondence: rgwhite@liverpool.ac.uk

'Institute of Life and Human Sciences, University of Liverpool, Brownlow Hill, Liverpool L69 3BX, UK

${ }^{3}$ University of Liverpool, G.10, Ground floor, Whelan Building, Quadrangle, Brownlow Hill, Liverpool L69 3GB, UK

Full list of author information is available at the end of the article
}

C C The Author(s). 2020 Open Access This article is licensed under a Creative Commons Attribution 4.0 International License, which permits use, sharing, adaptation, distribution and reproduction in any medium or format, as long as you give appropriate credit to the original author(s) and the source, provide a link to the Creative Commons licence, and indicate if changes were made. The images or other third party material in this article are included in the article's Creative Commons licence, unless indicated otherwise in a credit line to the material. If material is not included in the article's Creative Commons licence and your intended use is not permitted by statutory regulation or exceeds the permitted use, you will need to obtain permission directly from the copyright holder. To view a copy of this licence, visit http://creativecommons.org/licenses/by/4.0/. The Creative Commons Public Domain Dedication waiver (http://creativecommons.org/publicdomain/zero/1.0/) applies to the data made available in this article, unless otherwise stated in a credit line to the data. 


\section{Introduction}

The number of forcibly displaced persons in 2018 exceeded 70.8 million worldwide [1]. Within this displaced group, the estimated number of people awaiting a decision on their application for asylum was 3.5 million, and an estimated 25.9 million individuals were recognized as refugees [1]. High income countries on average host 2.7 refugees per 1000 of population [1]. The stressful experiences that many asylum seekers and refugees (AS\&R) are exposed to during forced migration, and during resettlement in host countries, can have a profound impact on their mental health $(\mathrm{MH})$ including high rates of depression, anxiety and posttraumatic stress disorder [2]. However, comparatively less research attention has been allocated to exploring other indices of $\mathrm{MH}$ such as quality of life (QoL) in AS\&R populations.

\section{Quality of life}

QoL has been implicated in MH status. It is defined as an 'Individuals' perception of their position in life in the context of the culture and value systems in which they live and in relation to their goals, expectations, standards and concerns' ([3], p.1). As such, QoL is a broad ranging and multidimensional concept which includes an individual's subjective evaluation of their physical health, psychological state, level of independence, social relationships, personal beliefs and their relationship to their environment [4].

Whilst there is growing consensus over the multidimensionality of QoL, little research has focused on understanding the specific predictors and correlates thereof. This is specifically the case with regards to AS\&R populations, despite the existing evidence base for their high risk of developing mental disorders. The WHO estimates the prevalence of mental disorders, including depression, anxiety, post-traumatic stress disorder (PTSD), bipolar disorder and schizophrenia, in conflict-affected settings to be $22.1 \%$ at any time point in the populations assessed [5]. Evidence has shown that for AS\&R the effects of war-related events may persist for years and have been associated with lower QoL even when hostilities have ended [6, 7]. Akinyemi et al. [6] noted that QoL, together with occupational status, were the biggest threats to the mental health of refugee populations and called for attention to the overall QoL in order to support their long-term mental health. Similarly, Matanov et al. [7], found that traumatic war events were directly associated with lower QoL in war-affected communities in the Balkan countries, and experiencing more migration-related stressors was linked to lower QoL in refugee populations who had resettled in Western Europe. Simultaneously, the lack of studies evaluating the efficacy of interventions for increasing QoL in
AS\&R populations $[8,9]$ has been noted. Improving understanding about predictors and correlates of QoL in AS\&R populations will be important for guiding the foci of these interventions, and more broadly informing policies in high-income countries to support the local settlement, integration and long-term mental health of AS\&Rs.

The current paper is the first to systematically review evidence relating to predictors and correlates of QoL of AS\&Rs living in high-income countries. The specific aims of the review were to: 1 ) understand what factors are associated with QoL in AS\&R populations; 2) identify the methodological strengths and weaknesses of the research investigating QoL.

\section{Methods}

\section{Literature search}

Fourteen databases were systematically searched. A search strategy tailored to the aims of the review was applied to each database using the Kings College London library guide [10]. See appendix A for the list of databases which were searched and the full search strategy. Reference chaining was also carried out and five experts in the field of mental health of refugee populations were independently consulted to ensure the final list of included papers was exhaustive.

\section{Eligibility}

All quantitative peer-reviewed publications in English, Spanish or Dutch (languages spoken by the authors of this review) which used measures based on the four WHOQOL domains [4], explored predictors and correlates of the QoL of adult AS\&R populations residing in a high-income country (as classified by the World Bank ${ }^{1}$ ) at the time that the search was conducted were included. The exclusion of grey literature was used as a form of minimal quality assurance. Longitudinal evaluations of interventions were also excluded if a cross-sectional analysis between QoL and other variables were not performed at baseline. The search of databases was conducted up to the 5th of May 2020, and any studies that met inclusion criteria were included in the current review. Furthermore, additional papers identified through expert consultation were included.

$\mathrm{CB}$ and RA independently screened the titles and abstracts for inclusion. Articles rated as possible candidates by either $\mathrm{CB}$ or RA were added to a preliminary list. Working independently and in duplicate, both reviewers inspected the full texts of the preliminary list for inclusion. A consensus meeting was subsequently held

${ }^{1}$ Further information on the classification of countries per income can be found at: https://datahelpdesk.worldbank.org/knowledgebase/ articles/906519 
between $\mathrm{CB}$ and $\mathrm{RA}$ and remaining discrepancies were resolved through discussion with the research team.

\section{Data extraction and quality appraisal}

For each included study, CB extracted information on the publication year, country of publication, settings, populations, study design, assessment measures and key findings, which was peer-reviewed by RW. Once the data was extracted, $C B$ rated the quality of each individual study and RA peer reviewed the quality appraisal for a quarter of the studies.

\section{Data synthesis and analysis}

A narrative synthesis approach was used to analyze the data. The WHOQOL Group developed a conceptual framework for QoL that incorporates four domains [4]: physical, psychological, social relationships and environment. To support efforts to synthesize the research findings of the studies included in the current review, these four domains were used to group predictors and correlates of QoL investigated in the studies. Two authors ( $\mathrm{CB}$ and $\mathrm{RW}$ ) independently mapped the various correlates investigated in the studies onto these four domains, discrepancies were resolved through discussion.

Consideration was given to conducting a metaanalysis. Five studies reported significant relationship between QoL and the correlates in terms of a correlation coefficient (an $r$ statistic) and the statistical significance of this coefficient. Meta-analysis of correlation coefficients is methodologically complex due to the bounded nature of these statistics (i.e. that they can only take values between: -1 and +1 ) and furthermore, correlation coefficients were not reported with a measure of precision such as a confidence interval which would be required for meta-analysis $[11,12]$. Similarly, five studies also reported the relationship between QoL and the variables in terms of $\mathrm{t}$-statistics and corresponding $p$-values. Such statistics do not have an associated measure of precision and therefore cannot be combined within metaanalysis.

The only amenable statistical measure for metaanalysis to represent the relationship between QoL and the predictors were regression (beta) coefficients with accompanying confidence intervals. These were reported in $52 \%$ of studies. These act as continuous data and theoretically, synthesis of such data may be possible within a 'prognostic review' framework [13]. However, across the studies, the predictors included within regression models to examine the effects of these predictors on QoL varied widely. Therefore, due to anticipated very large heterogeneity originating from the wide range of predictors included within regression models (see Additional file 1), meta-analysis of these beta-coefficients was deemed to be potentially misleading and therefore inappropriate.

Instead, further consideration of the direction, strength and consistency of the correlates of overall QoL has been undertaken for the studies included in this review which reported correlational analysis. Cohen's [14] conventions were used to interpret the effect sizes; positive large correlation $(>0.50$ to +1.00$)$, positive moderate correlation (0.30 to 0.50$)$ and positive small correlation $(<0.30)$. Negative large correlation $(<-0.50$ to -1.00$)$, negative moderate correlation ( -0.30 to 0.50$)$ and negative small correlation $(>-0.30)$. Positive correlations indicate a relationship between two variables in which both variables move in the same direction (i.e. if mental health increases, QoL increases), whereas negative correlations indicate a relationship whereby both variables move in opposite directions (i.e. if depression decreases, QoL increases). Figure 2 provides a representation thereof.

The quality of the cross-sectional studies was assessed using the Appraisal tool for Cross-Sectional Studies (AXIS tool) [15]. Longitudinal studies were assessed using the Critical Appraisal Skills Programme [16]. The quality of the studies was independently rated by $\mathrm{CB}$. Additionally, RA rated a quarter of the cross-sectional studies $(N=5)$ and longitudinal studies $(N=2)$ in order to ensure a quality check was carried out. There was high agreement regarding quality assessment; items that were rated differently were resolved through discussion.

\section{Results}

The search identified 13.655 articles of which 23 met the inclusion criteria. Article selection is summarized in the PRISMA diagram presented in Fig. 1.

\section{Study characteristics}

A total of twenty-three studies met the inclusion criteria. Seventeen studies were conducted in Europe, two in Australia, two in Israel, one in the USA and one in Japan. Four studies used the same dataset, therefore there were two repeat samples. Sample sizes ranged from 22 to $663(\mathrm{Mdn}=119, \mathrm{IQR}=222)$, with a total sample of 3817 across studies including 2138 males, 1516 females, and 163 not specified. Studies that used the same dataset were only counted once. Eleven of the studies recruited individuals from a medical setting, and the rest were recruited from support agencies, reception facilities $(N=5)$, community events $(N=4)$ or other $(N=3)$. Seventeen studies reported cross-sectional data and six were longitudinal studies including one case control design. All studies used the WHOQOL-100, WHOQOL-BREF or the EUROHIS-QOL measures (see Table 1). 


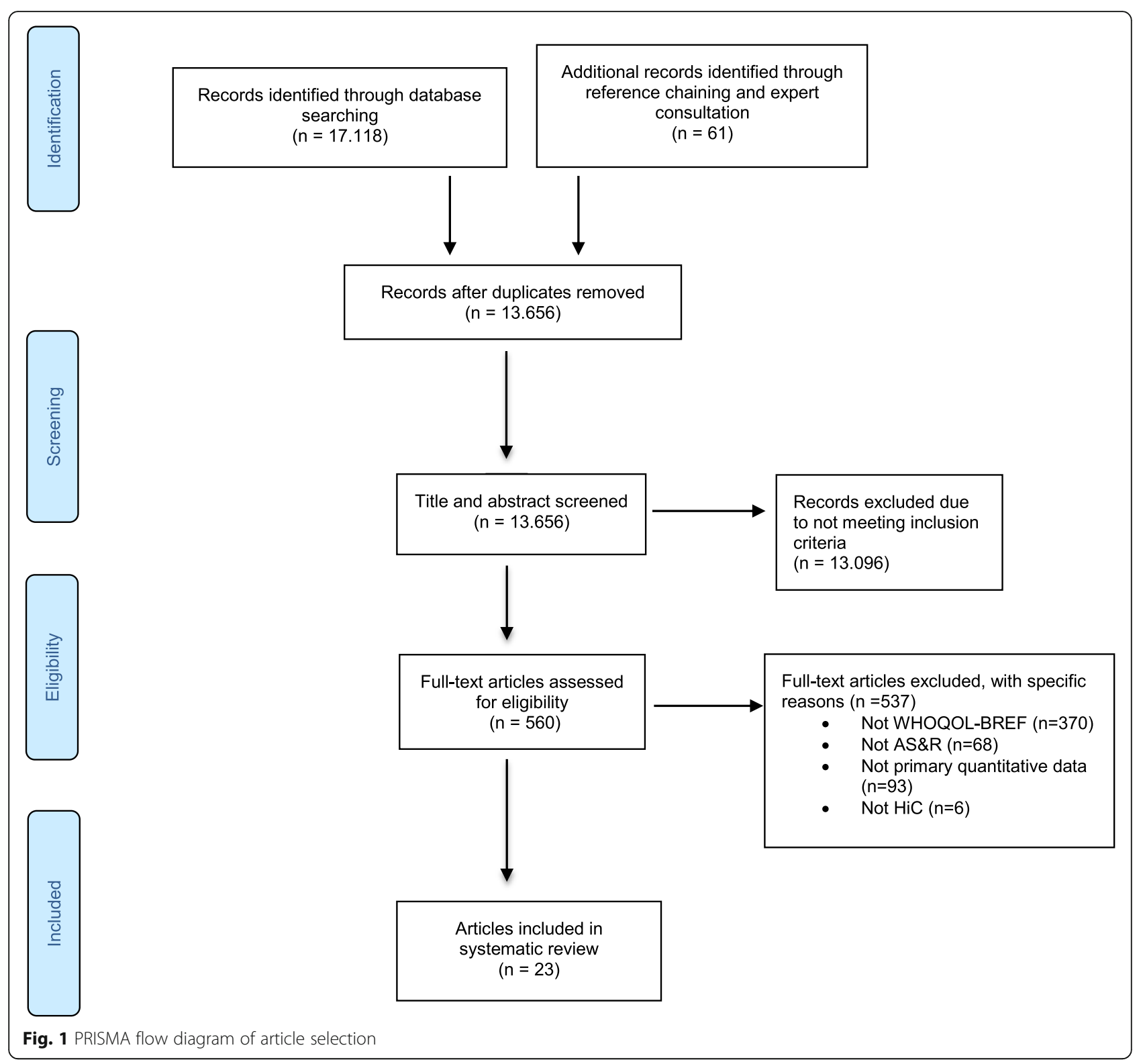

The WHOQOL-100 is the QoL questionnaire developed by the WHO [40]. It consists of 100 items, and each item is measured from on a 1 to 5 Likert scale. The internal consistency of the Danish version was high (Cronbach's $\alpha=0.97$ ), with a test-retest reliability of 0.70 [41]. Furthermore, it has been validated in refugee populations [42].

The WHOQOL-BREF is the abbreviated version of the WHOQOL-100 [4] and contains 26 questions. The internal consistency of the WHOQOL-BREF was high (Cronbach's $\alpha=0.86$ ), and demonstrated discriminant and construct validity (i.e. [43]). It has also been validated in refugee populations [44]. Lastly, the EUROHIS-QOL [45] is an 8-item index which is based on the WHOQOL-100 and WHOQOL-BREF.
Each item is measured using the 1 to 5 Likert scale. It has demonstrated high internal consistency (Cronbach's $\alpha=0.80$ ), and satisfactory convergent and discriminant validity [45].

\section{Quality of cross-sectional studies}

None of the seventeen cross-sectional studies met all 20 quality criteria of the AXIS tool, and although all of the cross-sectional studies met over half of the quality criteria, only 12 met $75 \%$ or more of these criteria. The study with the highest quality rating met nineteen of the quality criteria [22] and the study with the lowest quality rating met eleven of the quality criteria [24]. The quality assessment of each cross-sectional study can be found in Table 2. 
Boor et al. Conflict and Health

(2020) $14: 48$

Page 5 of 25

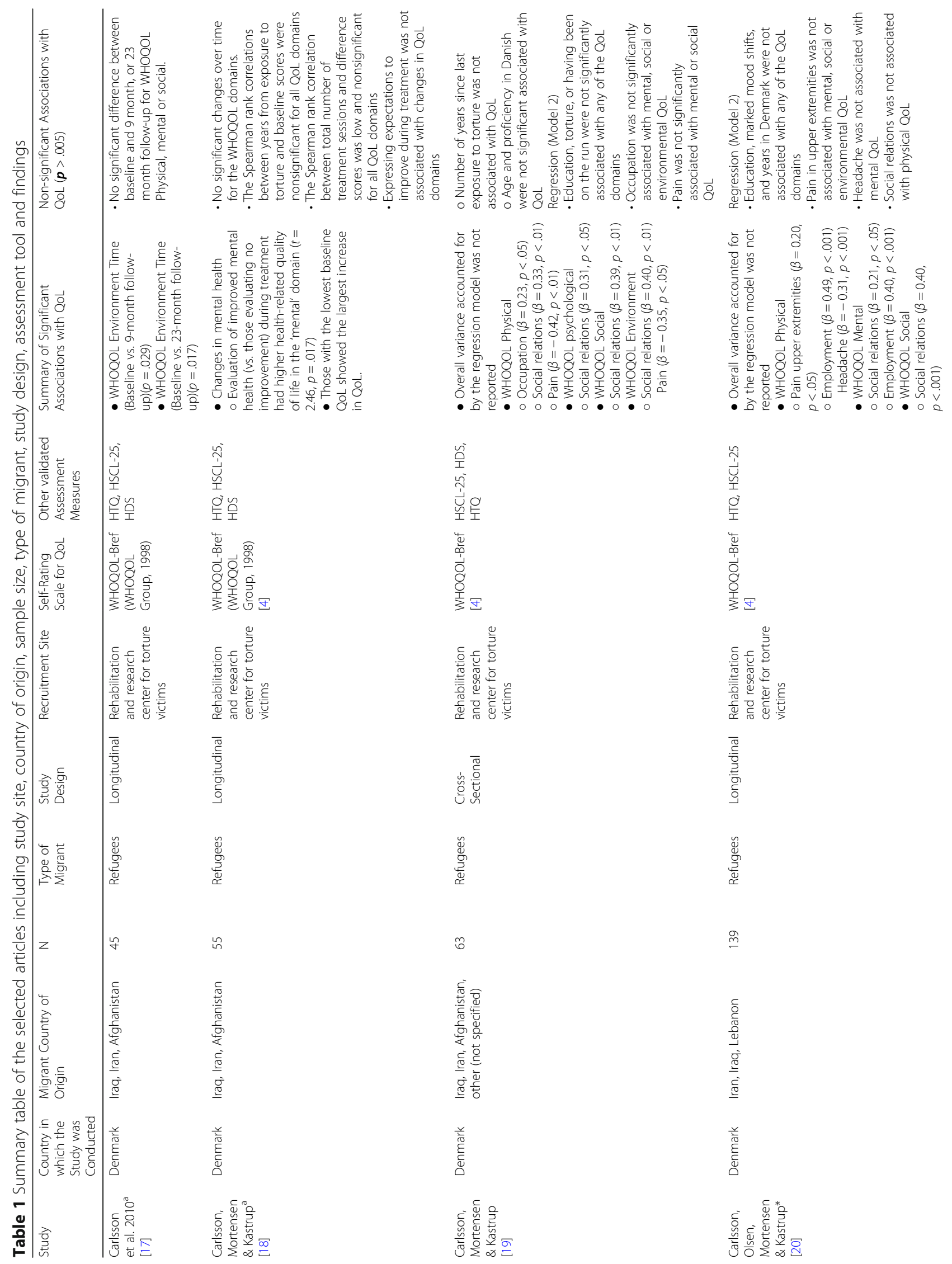




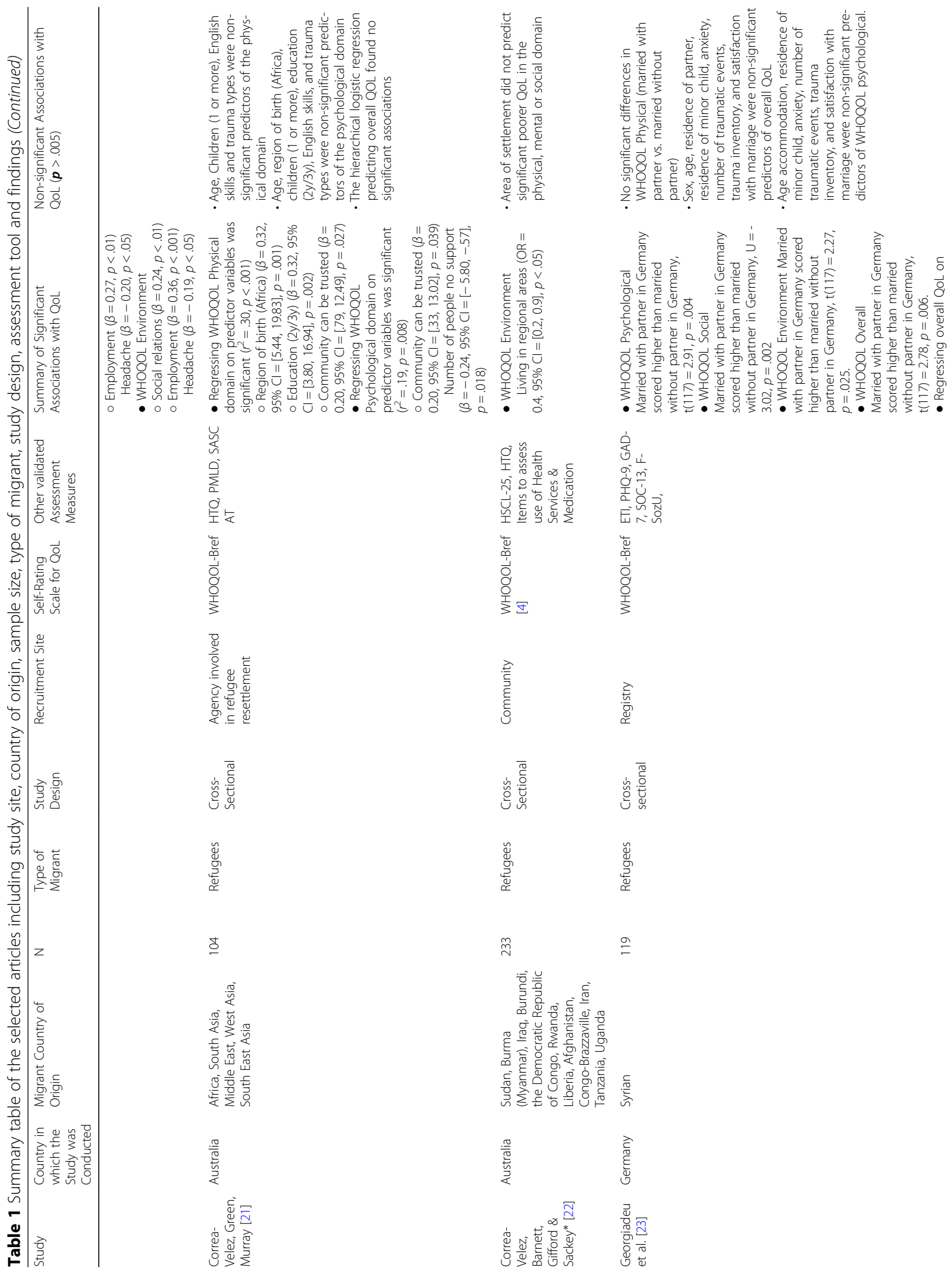




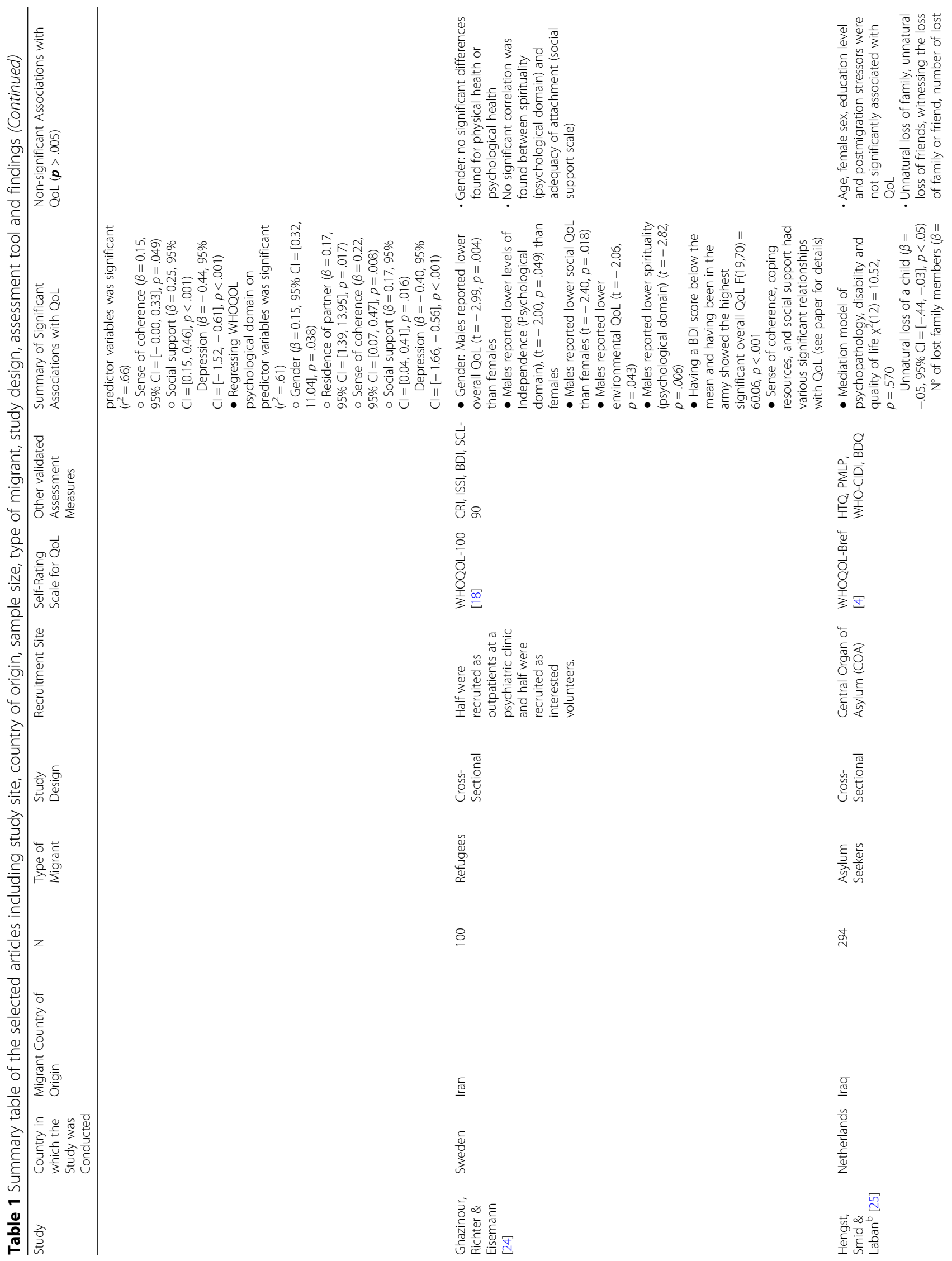




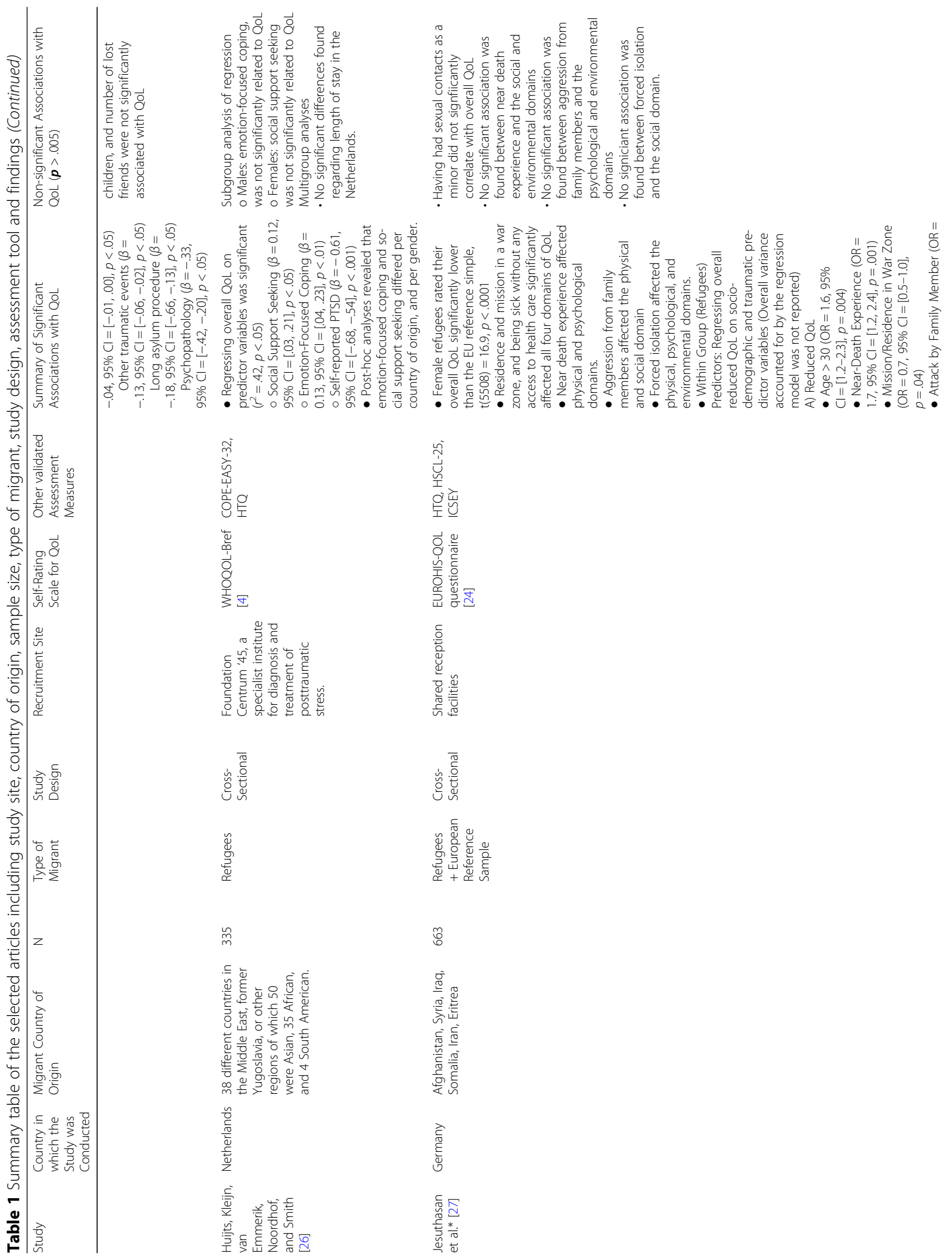




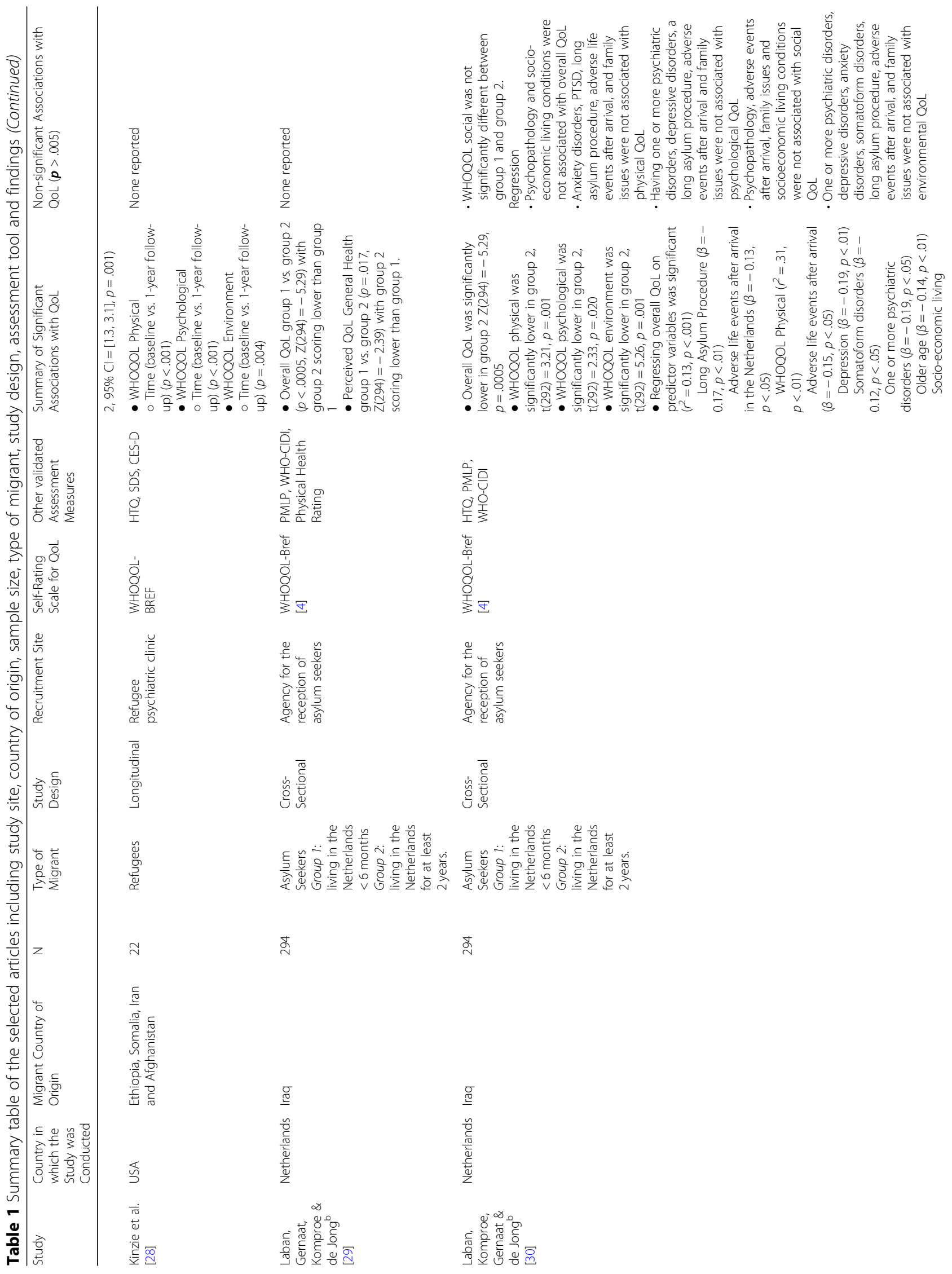




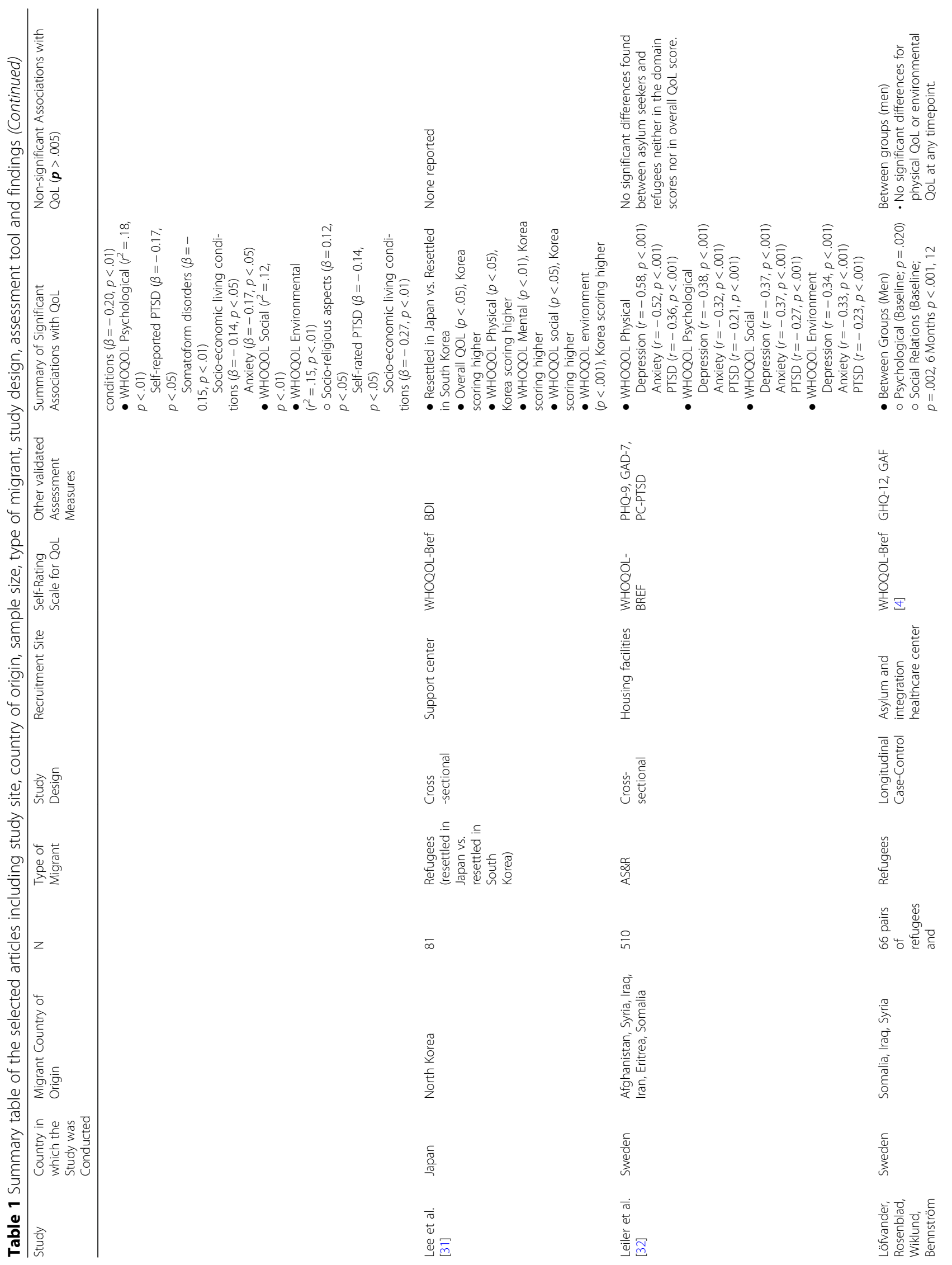




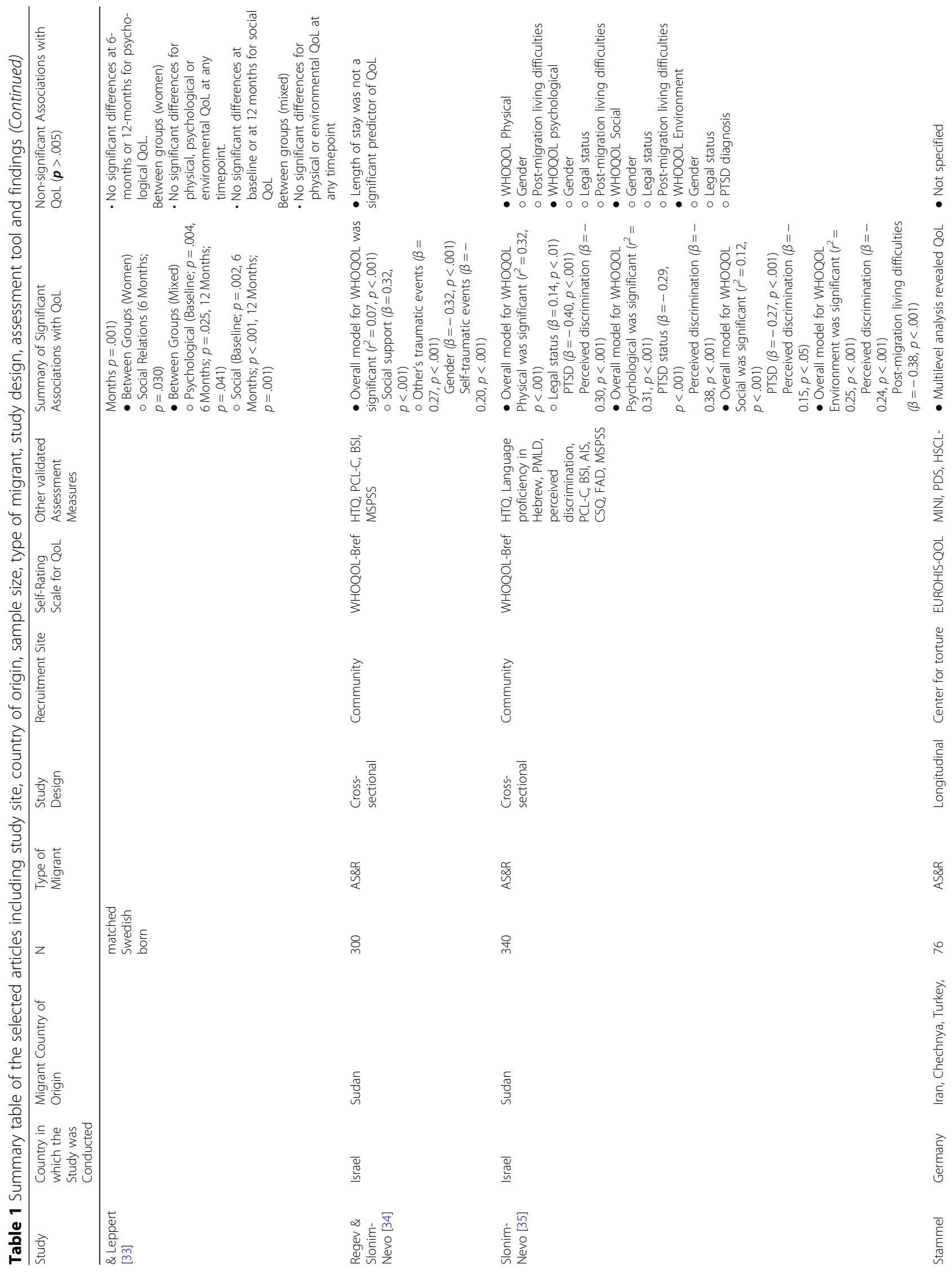




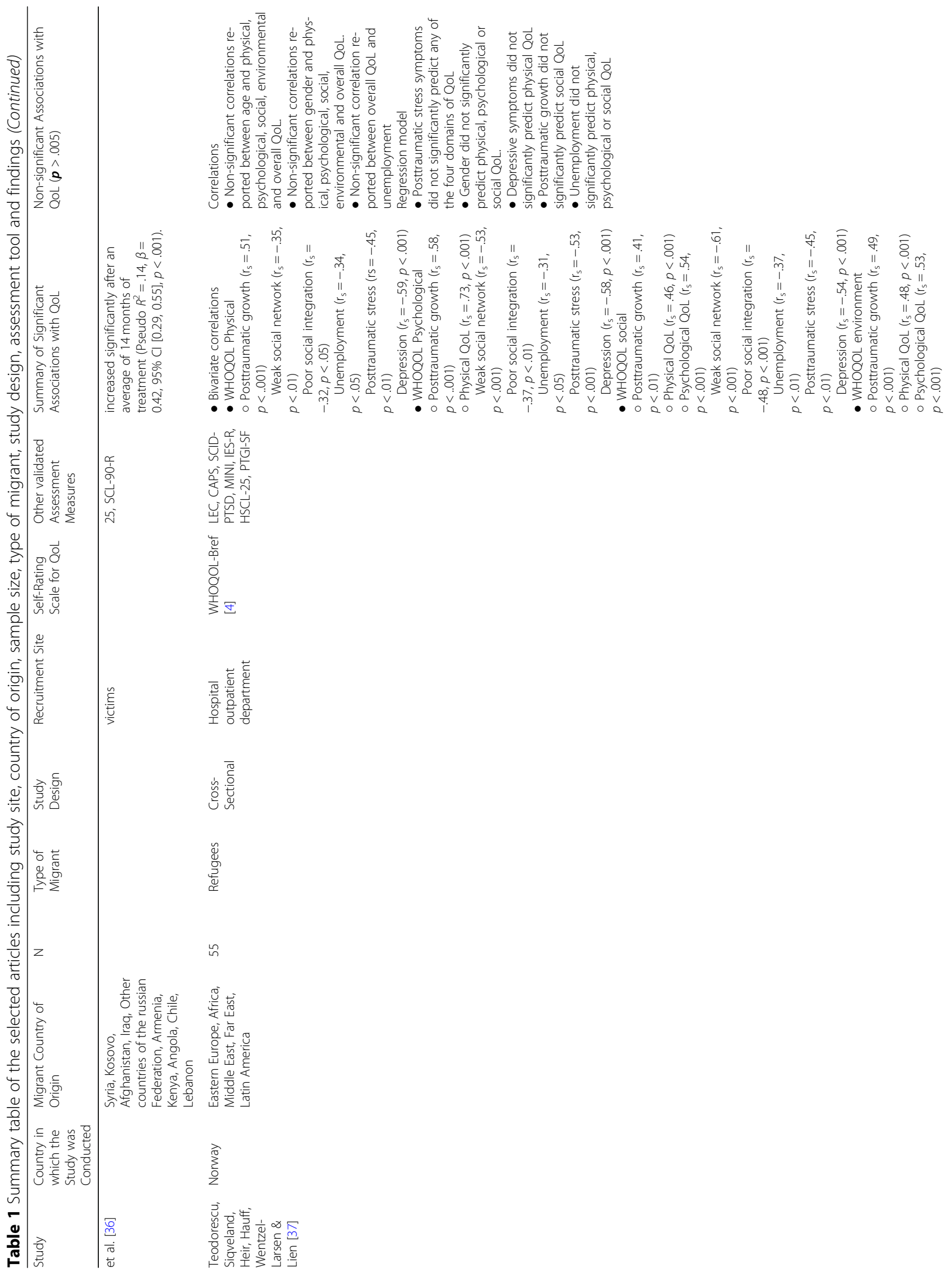




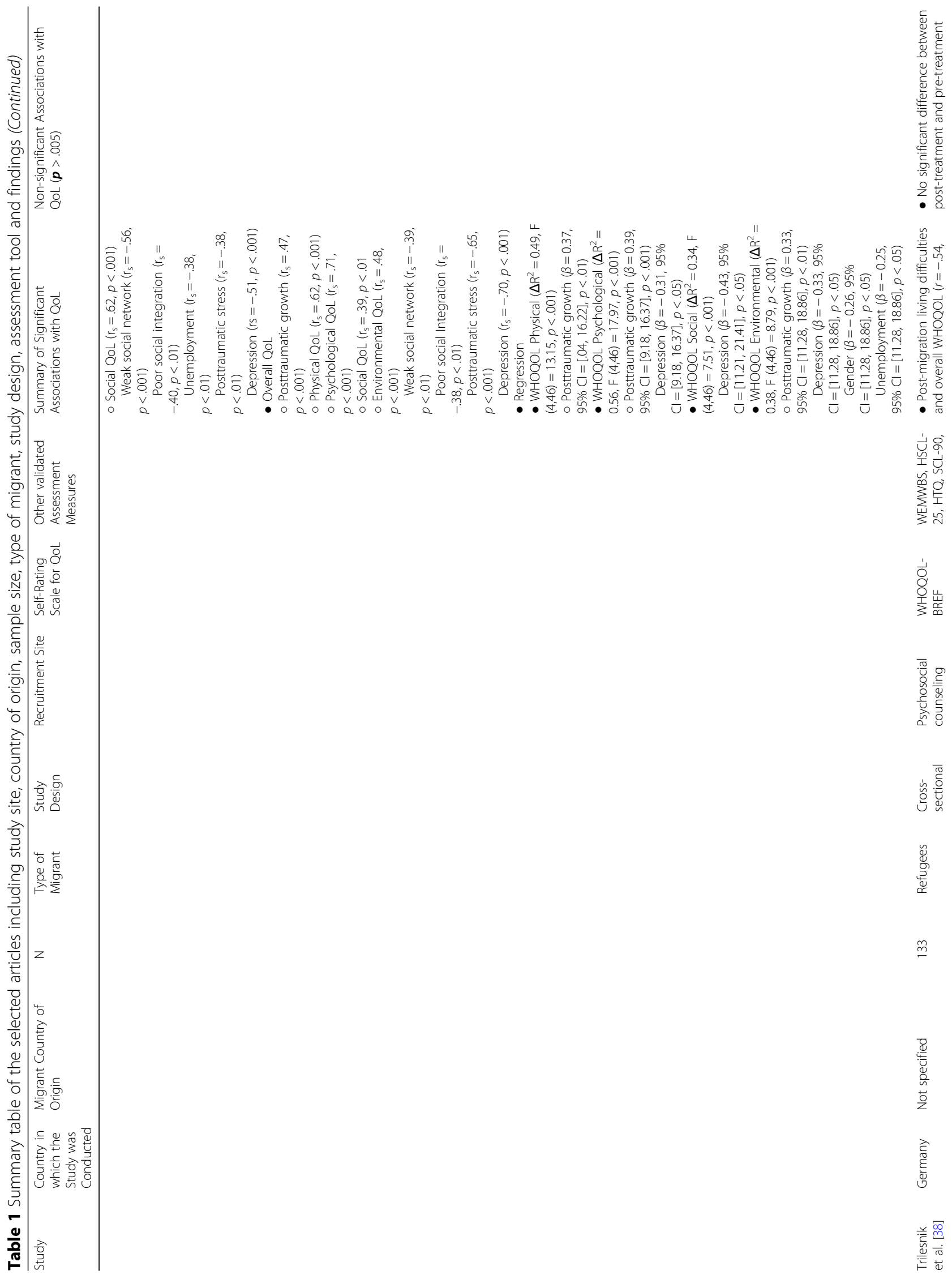




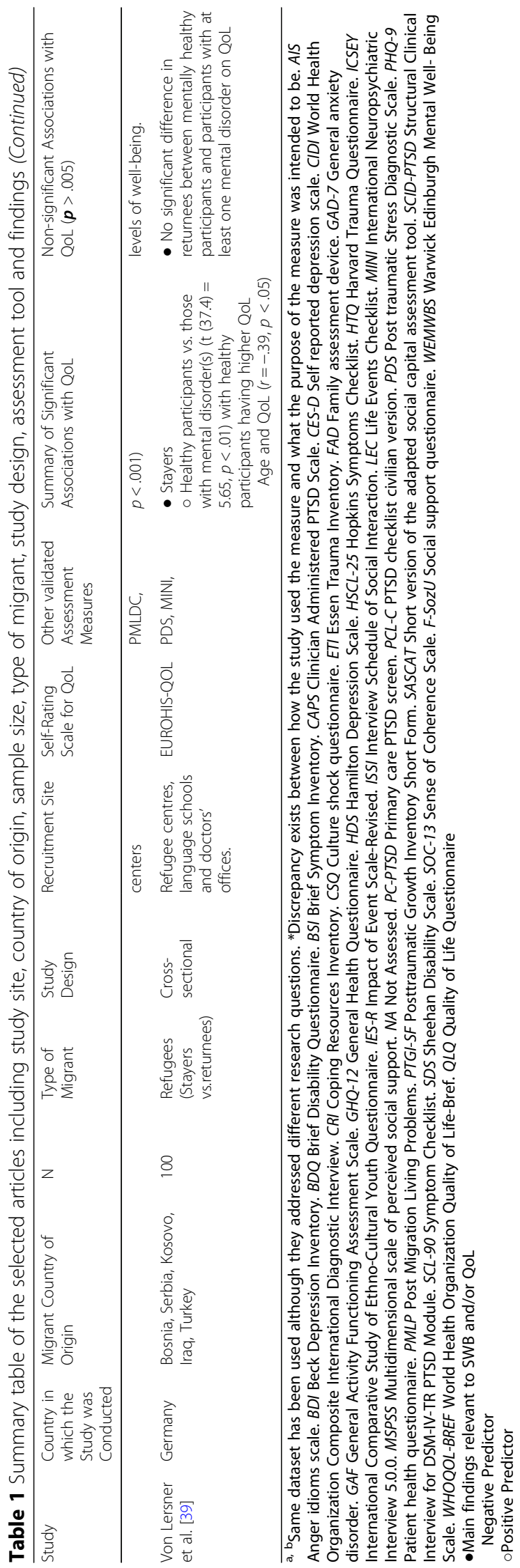


Table 2 Quality assessment of the included cross- sectional studies using the AXIS tool

\begin{tabular}{|c|c|c|c|c|c|c|c|c|c|c|c|c|c|c|c|c|c|}
\hline \multicolumn{18}{|l|}{ Quality assessment of the included cross- sectional studies using the AXIS tool } \\
\hline Axis tool items & 1 & 2 & 3 & 4 & 5 & 6 & 7 & 8 & 9 & 10 & 11 & 12 & 13 & 14 & 15 & 16 & 17 \\
\hline \multicolumn{18}{|l|}{ Aims/objectives of the study clear } \\
\hline \multicolumn{18}{|l|}{ Appropriate study design } \\
\hline \multicolumn{18}{|l|}{ Was the sample size justified? } \\
\hline \multicolumn{18}{|l|}{ Target/reference population clearly defined } \\
\hline \multicolumn{18}{|l|}{ Was the sample frame taken from an appropriate population base? } \\
\hline \multicolumn{18}{|l|}{$\begin{array}{l}\text { Was the selection process likely to select subjects/participants that were } \\
\text { representative of the target/reference population? }\end{array}$} \\
\hline \multicolumn{18}{|l|}{ Were measures undertaken to address and categorize non-responders? } \\
\hline \multicolumn{18}{|l|}{$\begin{array}{l}\text { Were the outcome variables measured appropriate to the aims of the } \\
\text { study? }\end{array}$} \\
\hline \multicolumn{18}{|l|}{$\begin{array}{l}\text { Were the risk factor and outcome variables measured correctly using } \\
\text { instruments/measurements that had been trialed, piloted or published } \\
\text { previously? }\end{array}$} \\
\hline \multicolumn{18}{|l|}{$\begin{array}{l}\text { Is it clear what was used to determine statistical significance and/or } \\
\text { precision estimates? }\end{array}$} \\
\hline \multicolumn{18}{|l|}{ Were the methods sufficiently described to enable them to be repeated? } \\
\hline \multicolumn{18}{|l|}{ Were the basic data adequately described? } \\
\hline \multicolumn{18}{|l|}{ Does the response rate raise concerns about non-response bias? } \\
\hline \multicolumn{18}{|l|}{ If appropriate, was information about non-responders described? } \\
\hline \multicolumn{18}{|l|}{ Were the results internally consistent? } \\
\hline \multicolumn{18}{|l|}{ Were the results for the analyses described in the methods, presented? } \\
\hline \multicolumn{18}{|l|}{ Were the authors' discussions and conclusions justified by the results? } \\
\hline \multicolumn{18}{|l|}{ Were the limitations of the study discussed? } \\
\hline \multicolumn{18}{|l|}{$\begin{array}{l}\text { Sources of funding or conflicts of interest that may affect the authors' } \\
\text { interpretation of the results? }\end{array}$} \\
\hline Was ethical approval or consent of participants attained? & & 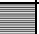 & & & & & 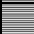 & & & & & & & & & & \\
\hline
\end{tabular}

$1=$ Carlsson et al. [19], $2=$ Lee et al. [31], $3=$ Correa-Velez et al. [22], $4=$ Correa-Velez et al. [21], $5=$ Georgiadou [23], $6=$ Ghazinour et al. [24], $7=$ Hengst et al. [25], $8=$ Huijts et al. [26], $9=$ Jesuthasan et al. [27], $10=$ Laban et al. [29], $11=$ Laban et al. [30], $12=$ Leiler et al. [32], $13=$ Regev et al. [34], $14=$ Slonim-Nevo et al. [35], $15=$ Teodorescu et al. [37], $16=$ Trilesnik et al. [38], $17=$ Von Lersner et al. [39]

$\square$ Quality met

$\square$ Quality not met

$\square$ Unclear

Many methodological weaknesses were noted. Firstly, sample size justification (i.e. power calculation) was only reported by one study [38]. Five studies were unclear regarding sample selection, and one study was unclear regarding taking the sample frame from an appropriate population base [24]. Secondly, there were significant concerns regarding response bias as eight studies did not make a clear attempt to quantify the level of nonresponders. Thirdly, five studies were unclear on standards used for determining statistical significance and/or precision estimates in their results section. This was due to insufficient detail regarding data management, significance levels, effect sizes and/or confidence intervals. Lastly, eight studies did not clearly report sources of funding and/or conflicts of interest. Five studies were not clear on whether ethical approval or consent had been obtained.

\section{Quality of longitudinal studies}

Table 3 provides details about the quality of the longitudinal studies. Five studies clearly defined their primary outcome, one did not [28]. Five also used validated measures, one did not [18]. All of the studies identified confounding factors, however two did not take them into account in the analysis, and two studies were unclear. Overall, a range of follow-up periods were used; 6months, 7-months, 9-months, 12-months, 14-months, 23-months and 10-years.

The two biggest limitations were that all studies lacked statistical precision (e.g. failing to state the confidence 


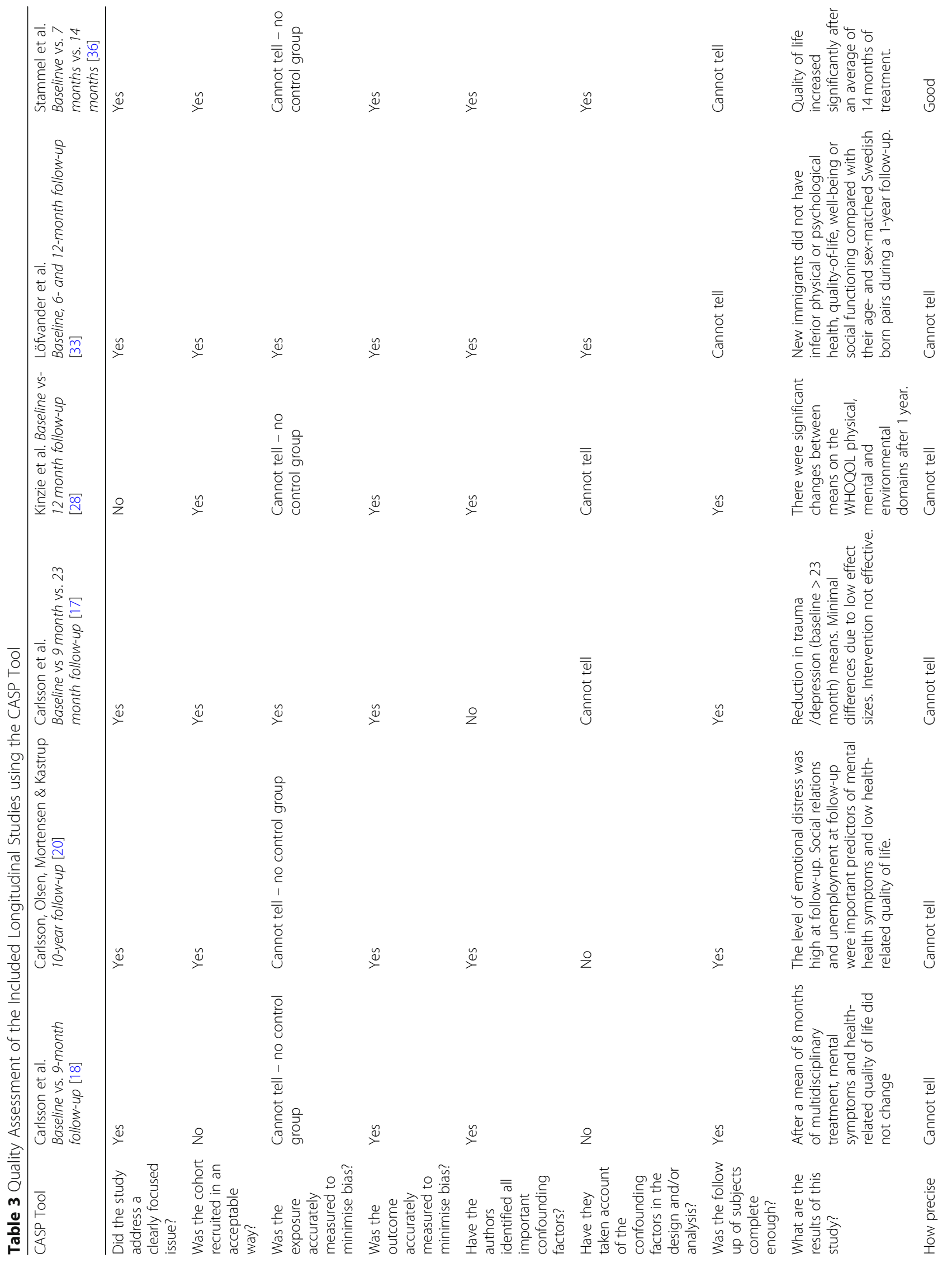




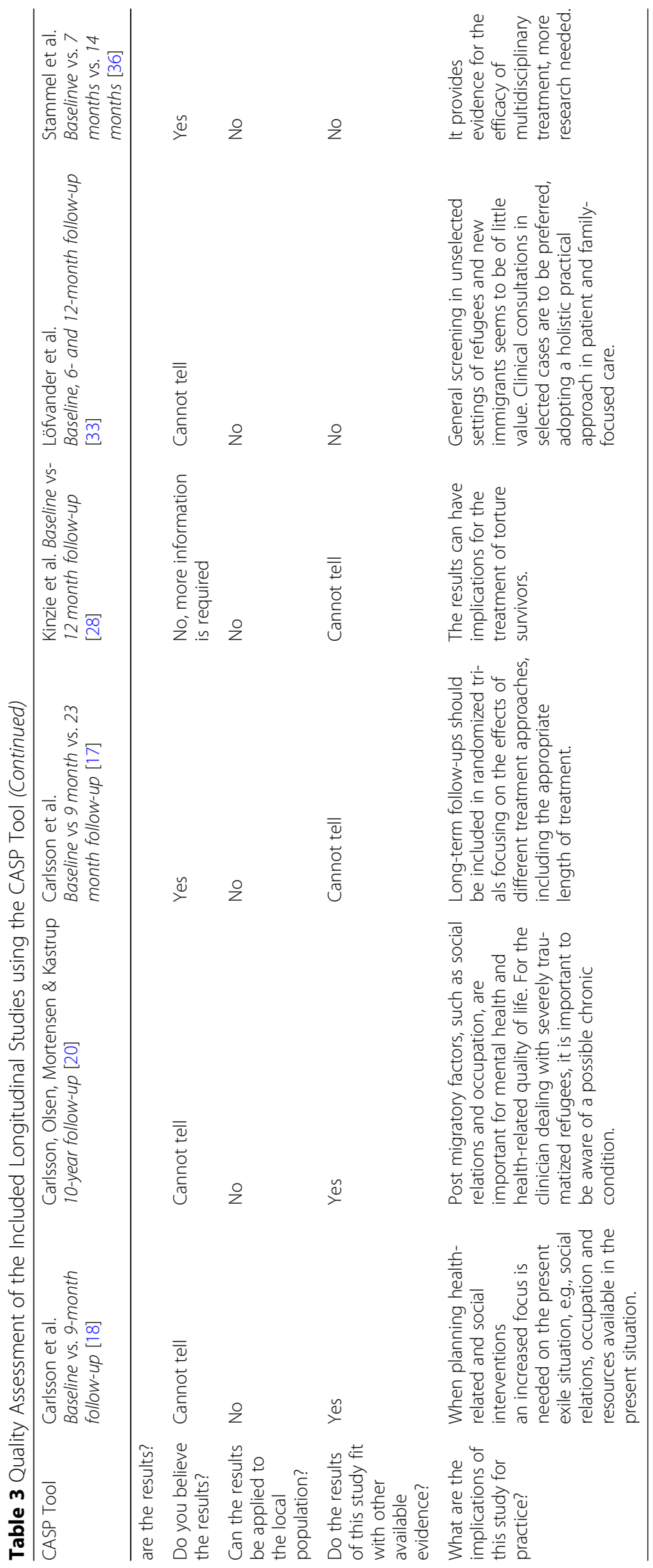


intervals or effect size), and the results cannot be applied to the local population as studies were conducted on very specific samples. There was a shortage of detail regarding follow-up assessments - three studies did not provide enough information on non-responders $[18,20$, 33]. All but one [36] study did not clearly report effect sizes, variance accounted for by regression models, and/ or the confidence intervals for the results. The quality assessment of each individual longitudinal study can be found in Table 3.

\section{Overall quality of life (oQoL)}

All WHOQOL-BREF domains positively correlated with each other [37]. There was evidence of differences in oQoL according to the time that had passed since arriving in the host country - Two studies, using the same sample, found that asylum seekers who had recently resettled ( $<6$ months) rated their oQoL higher than those who had lived in the host country for at least 2 years $[29,30]$. Simultaneously, Stammel et al. found that refugees' oQoL increased after 14 months of multidisciplinary treatment.

In terms of physical correlates, significant gender differences were found - males reported lower oQoL than females [24], and Regev et al. [34] found gender to be a significant negative predictor of oQoL, however the coding of variables was not reported. When compared to a non-refugee EU sample, a female refugee sample rated their oQoL significantly lower [27]. Being older (> 30 years) predicted lower oQoL [27], and was a negative correlate of oQoL [39].

Psychological associations with lower oQoL included, self-rated PTSD [26], posttraumatic stress [37], depression [23, 24, 37] and having one or more mental disorders, including depression, anxiety, PTSD and somatoform disorders [25]. Furthermore, experiencing the following adverse events was negatively associated with oQoL; near-death experiences [27], self-traumatic events [34], forced isolation [27], adverse events post-resettlement [30], and other traumatic experiences $[25,34]$.

When compared to individuals with a mental disorder, healthy individuals reported higher oQoL [39]. Sense of coherence was positively associated with oQoL [23, 24], with males reporting a significantly lower sense of coherence than females [24]. Exposure to other people's traumatic events [34] and posttraumatic growth [37] were positive predictors of oQoL; and coping strategies [24, 26], availability and adequacy of attachment [24] correlated with increased oQoL. According to one study, coping strategies only led to an increase in oQoL for females [26]. Exposure to other people's traumas was interpreted by the authors as potentially providing validation for people's own experiences [34].
Weak social networks and poor social integration were social correlates of low oQoL [37]. Specific events that predicted lower oQoL included the unnatural loss of a child [25], attacks by family members ${ }^{2}$ [27], and number of lost family members [25].

Positive social predictors of oQoL focused on having social support $[23,26,34]$. Additionally, social integration [24] and having a spouse in the host country [23, 27], were associated with higher oQoL. One study suggested that social support was only a significant predictor for males [26].

Three of the environmental predictors that were investigated predicted low oQoL; prior mission/residence in a war zone [27], being sick without access to healthcare and long asylum procedures $[25,30]$. Post-migration living difficulties negatively correlated with oQoL [38]. Similarly, one study found that North Korean refugees resettled in South Korea vs. those resettled in Japan had higher QoL, which the authors interpreted as being due to difficulties adapting to a new culture [31]. No positive predictors or correlates of eQoL were found.

The consideration of the direction, strength and consistency of the correlational analyses of the correlates of oQoL reported across studies is summarized in Fig. 2. For oQoL, both the strongest positive and negative correlations were found by Ghazinour et al. The strongest positive correlate found was between physical coping resources and psyQoL $(r=0.82, p<.001)$ and the strongest negative correlation found was between depression and psyQoL $(r=-0.86, p<.001)$ [24]. However, this study reported the lowest quality of the 23 studies included. The majority of strong positive correlations found for oQoL were mental correlates.

\section{Physical quality of life (pQoL)}

Laban et al. [30] found that asylum seekers who had recently resettled ( $<6$ months) rated their pQoL higher than those who had lived in the host country for at least 2 years [30]. On the other hand, Kinzie et al. [28] reported $\mathrm{pQoL}$ improved over time (1 year) for refugees who were undergoing treatment. Older age was a negative predictor of pQoL [30]. Negative Physical correlates of $\mathrm{pQoL}$ in AS\&R were physical pain [19] and headaches [20]. The only positive Physical predictor found was region of birth, specifically being African was a positive predictor of pQoL [21].

Negative Psychological predictors of $\mathrm{pQoL}$ included diagnoses of depression [30], somatoform disorders [30], PTSD [35], having one or more mental disorders [30], and adverse life events post-migration [30]. Negative correlates of pQoL found were similar; depression [24, 32, 37],

${ }^{2}$ This terminology was replicated from the study itself, the authors of the study do not specify what is meant specifically with this term. 

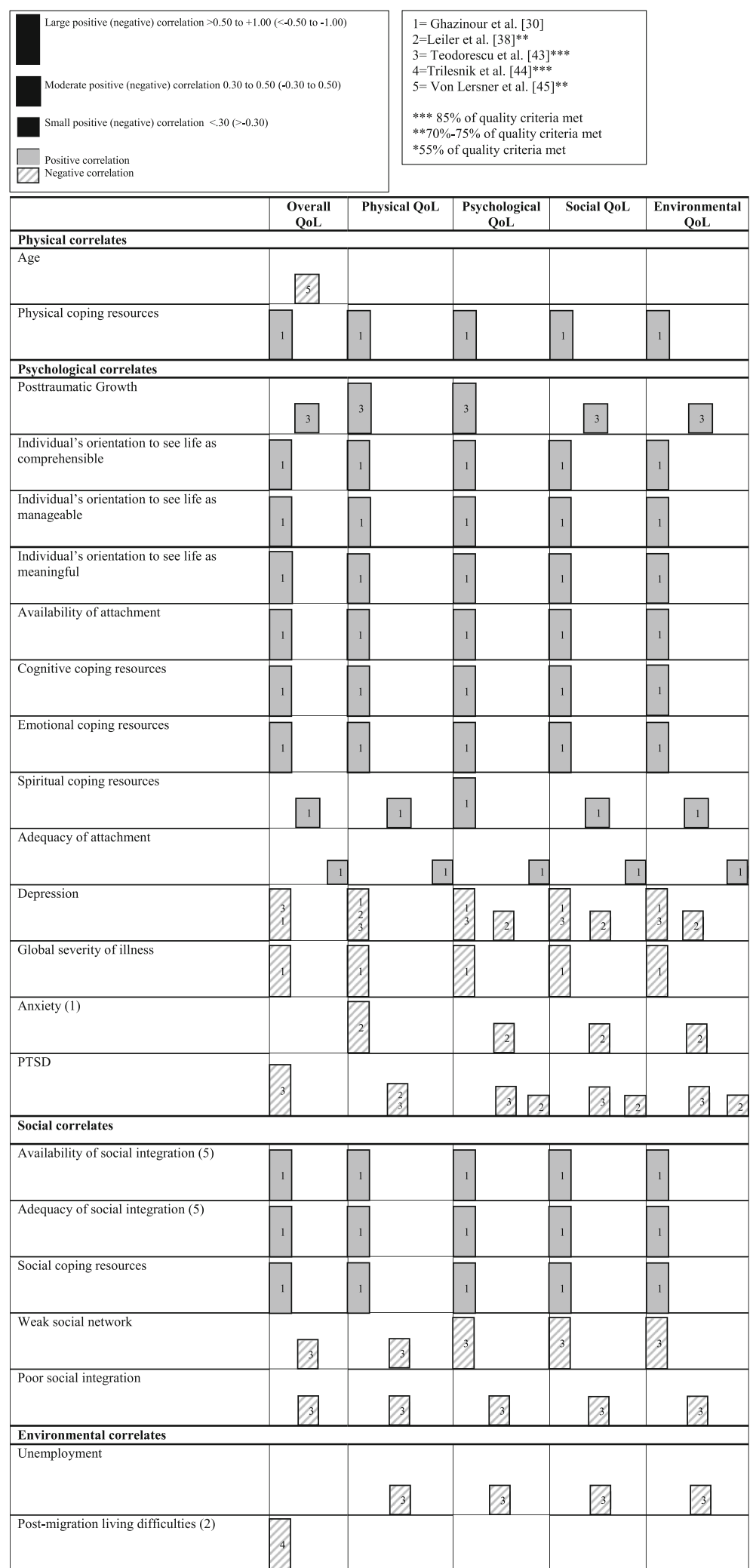

Fig. 2 A harvest plot indicating the positive and negative correlations of overall QoL and the four QoL domains. All findings are from cross-sectional studies 
anxiety [32] and PTSD [32, 37]. Contrarily, coping strategies [24], availability and adequacy of attachment [24], were correlated with increased pQoL [37]. Posttraumatic growth was a positive predictor of pQoL [37].

One study reported on negative social predictors of pQoL and found that perceived discrimination [35] negatively predicted pQoL. Weak social networks [37] and poor social integration [37] were negatively correlated with pQoL. Positive social predictors were having social relations $[19,20]$ and feeling that most people in the community can be trusted [21]. Additionally, social integration was positively correlated with pQoL [24].

Living conditions post-resettlement, specifically socioeconomic conditions [30] was a significant negative environmental predictor of $\mathrm{pQoL}$. Unemployment was significantly negatively correlated with $\mathrm{pQoL}$ but was not a significant predictor [37]. Being employed [19, 20] and having completed either secondary or tertiary education [21] were significant environmental predictors of increased pQoL $[19,20]$. Additionally, legal status increased $\mathrm{pQoL}$, with refugees reporting higher $\mathrm{pQoL}$ than asylum seekers [35]. Lastly, place of resettlement was significant, as one study found that North Korean refugees resettled in South Korea vs. those resettled in Japan had higher QoL, which the authors interpreted as being due to difficulties adapting to a new culture [31].

\section{Psychological quality of life (psyQoL)}

Differing results were found for asylum seekers and refugees on psyQoL over time. Laban et al. [30] found that asylum seekers who had recently resettled ( $<6$ months) rated their $\mathrm{pQoL}$ higher than those who had lived in the host country for at least 2 years [30], whereas Kinzie et al. [28] reported psyQoL improved over time (1-year) for refugees who were undergoing multidisciplinary treatment [28]. Group comparisons over time between refugees and a non-migrant sample also showed that refugees scored significantly higher on psyQoL outcomes at baseline, 6 months and 12 months [33].

The only physical predictor for psyQoL was gender, with males reporting higher psyQoL overall [23]. Males also reported lower levels of independence and spirituality than females, which belong to the psychological domain [24].

Psychological predictors found to decrease psyQoL were depression [23, 37], anxiety [36,], PTSD [30, 35], and somatoform disorders [30]. Negative correlates for psyQoL found were similar; depression [24, 32, 37], anxiety [32] and PTSD [32, 37].

Psychological correlates for an increased psyQoL were self-evaluations of improved $\mathrm{MH}$ during treatment [18] coping strategies [24], and availability and adequacy of attachment [24]. Sense of coherence and posttraumatic growth [37] positively predicted psyQoL [23].
Negative social predictors reported were perceived discrimination [35], and number of key persons who provide no support [21]. Having a weak social network and poor social integration negatively correlated with psyQoL [37]. Findings on positive social predictors relevant to psyQoL highlighted the importance of social support $[19,20,23]$, feeling that most people in the community can be trusted [21], and having one's spouse in the host country [23]. Additionally, social integration [24] positively correlated with psyQoL.

The only significant negative environmental predictor of psyQoL was poor socio-economic living conditions post-resettlement [30]. Unemployment was a negative correlate [37]. Lastly, place of resettlement was significant as one study found that North Korean refugees resettled in South Korea vs. those resettled in Japan had higher QoL [31].

\section{Social quality of life (sQoL)}

There were two physical correlates of sQoL - having headaches predicted lower sQoL [20], and Gender. Löfvander et al. [33], noted that whereas the male refugees had higher sQoL compared to Swedish born controls (matched for age and gender) at the three assessment points (baseline, 6 months and 12-month follow-up), female refugees had significantly higher sQoL relative to Swedish born matched controls at baseline assessment only. Another study reported males had lower sQoL than female refugees [24].

Negative psychological correlates of SQoL reported were; depression [24, 32, 37], anxiety [32], PTSD [32], and posttraumatic stress [37]. PTSD [35] and depression [37] were negative predictors of sQoL. Availability and adequacy of attachment [24], and coping strategies [24] were positively correlated with sQoL, and posttraumatic growth positively predicted sQoL [37]. Perceived discrimination [35], was a significant negative social predictor of sQoL. Simultaneously, weak social network [37], and poor social integration [37] were negatively correlated with sQoL. Social integration [24] and being married with a spouse in the host country [23] were positively correlated with sQoL, and social relations $[19,20]$, positively predicted sQoL.

Employment was the only environmental predictor found to increase sQoL [20], and unemployment was found to decrease sQoL [37] Additionally, one study found that North Korean refugees resettled in South Korea vs. those resettled in Japan had higher QoL, which the authors interpreted as being due to difficulties adapting to a new culture [31].

\section{Environmental quality of life (eQoL)}

Three studies revealed the eQoL increased over time for refugees, after 9-months [17], 12-months [28] and 23month follow-up [17]. 
Laban et al. [30] found that asylum seekers who had recently resettled ( $<6$ months) rated their eQoL higher than those who had lived in the host country for at least 2 years [30].

In terms of negative physical predictors of eQoL, studies reported on the presence of pain [19] and headache [20]. Gender was also a predictor of eQoL; however, the authors did not specify how gender was coded [37]. However, Ghazinour et al. [24], found that males reported lower eQoL than females.

The negative psychological predictors of eQoL were selfrated PTSD [30], and depression [37]. Negative correlates found were similar; depression [24, 32], anxiety [32] and PTSD [32] negatively correlated with pQoL. Positive psychological correlates of eQoL were coping strategies [24], availability and adequacy of attachment [24]. Posttraumatic growth was a positive predictor of eQoL [37].

Perceived discrimination [35], was a significant negative predictor of eQOL. Poor social integration and having a weak social network [37] were negatively correlated with eQOL. The significant positive social predictor identified for eQOL was having social relations $[19,20]$. Social integration [24] positively correlated with eQoL and having one's spouse in the host country was associated with higher eQoL, as compared to not having one's partner in the host country [23].

The negative environmental predictors found comprised socio-economic living conditions post resettlement (including living in regional areas as opposed to central areas) [22, 30], post-migration living difficulties [35], unemployment [37], and socio-religious aspects, such as a lack of contact with people of the same religion [30]. The significant positive environmental predictor of eQoL was being employed [20]. Additionally, place of resettlement was found to be significant in two studies; Correa-Velez et al. [22] found that living in regional areas was a positive predictor of eQoL, and Lee et al. [31] found that North Korean refugees resettled in South Korea vs. those resettled in Japan had higher QoL.

\section{Differences between asylum seekers and refugees}

Sixteen of the included studies focused on refugees, three on asylum seekers and four used mixed samples or terminology. Only nine studies (39.1\%) gave the specific criteria used to define their sample as either a refugee or asylumseeking population (i.e. by law). This is important as some studies used mixed terminologies or did not distinguish between the two. Given that asylum seekers and refugees constitute different populations with different needs, this distinction is important. Only two studies specifically compared asylum seekers to refugees [32, 35]. Leiler et al. [32] found no significant differences between them on any of the four QoL domains nor in oQoL. Slonim-Nevo [35] did find that having a legal status positively predicted pQoL.
Similarly, long asylum procedures were found to be a negative predictor for oQoL by all three studies that focused exclusively on asylum seekers $[25,29,30]$. However, Laban et al. [30] did not find long asylum procedures to be a significant predictor for $\mathrm{pQoL}$ specifically. Furthermore, for asylum seekers, QoL did not appear to improve over time whereas for refugees findings suggest that it does.

\section{Discussion}

To date, there has been a paucity of efforts to synthesize evidence relating to predictors and correlates of QoL of AS\&Rs. The current review sought to address this gap, so that policy makers and organizations working to support AS\&Rs in high-income countries can be guided by an improved understanding about what enhances the lived experience of AS\&Rs. Key findings across the various forms of QoL (overall, physical, psychological, social and environmental) were that having established social networks and social integration were associated with higher QoL, whereas having mental disorders (i.e. PTSD or depression) was strongly associated with reduced QoL. Physical predictors and correlates were the least reported.

Psychological predictors and correlates (including the presence of mental disorders) of QoL were the most extensively studied and reported across studies. The predictors and correlates of QoL noted in the current review can be compared with predictors of common mental disorders (CMD) identified in previous reviews. For example, Bogic et al. [46] found that poor postmigration socio-economic status including unemployment, low income, poor host language proficiency and lack of social support were each associated with depression experienced by war-affected refugees. These findings overlap with those found in the current review. However, there were also important points of distinction; the current review showed that having a spouse was positively associated with increased QoL, whereas Bogic et al. [46] did not find any consistent association between marital status and mental disorders. Furthermore, this review showed that positive coping strategies were highly associated with increased QoL, whereas Bogic et al. [46] indicated that these factors had not been assessed in studies exploring mental disorders experienced by war-affected refugees. To ensure that AS\&Rs are afforded the opportunity to enjoy full and meaningful lives, it will be important to understand and address not only factors associated with mental disorders, but also those uniquely associated with QoL.

The associations that QoL had with various social factors and environmental factors, point to the value of extensive integration programs that include housing and employment assistance [47]. Unfortunately, however, in many high-income countries, AS\&Rs face social exclusion, restricted employment opportunities, and/or below 
average earnings [48]. The current review highlighted that having weak social networks, and poor social integration were both moderately correlated with lower overall QoL. Those involved in developing migrant integration policies need to be cognizant of the associations that QoL have with various aspects of the socioecological context that AS\&Rs live in. Most European governments and other OECD countries outside Europe have imposed employment bans or time constraints to asylum seekers entering the labor market $[49,50]$. Although asylum policies vary by country, region, and even over time within a country, such policies generally lead to long waiting periods in which asylum seekers find themselves in a legal and social limbo, without the ability to work and integrate. Research has shown that longer waiting times to obtain a refugee status strongly reduces employment integration of refugees (i.e. [51-53]) and can also reduce social integration (i.e. [54, 55]). Therefore, the findings of the current review should be considered by policymakers as being consistent with a need to reduce asylum procedure times, in order to promote socio-economic integration, reduce the risk of marginalization and mental ill-health, and overall increase the QoL of AS\&R populations. The discourse must shift from a narrative regarding AS\& $R$ as being a burden on society to seeing their support as an investment in the social and economic framework of the host country.

Regarding methodological quality, studies had moderate to good quality overall with more recent publications generally scoring higher on quality assessment. There was a tendency to recruit opportunistic samples through health centers, which may have resulted in a bias towards AS\&R who were already seeking care and with greater support systems rather than more marginalized individuals. This limits the generalizability of findings. Evidence of basic design flaws, and the predominance of cross-sectional methodologies were important limitations of the available evidence base. Moving forward more transparency is required regarding sampling procedures and non-responders. Furthermore, authors need to clearly state sources of funding and possible conflicts of interest that may have led to outcome bias.

\section{Future research and implications}

The current review has highlighted a need for research to further explore factors positively associated with QoL. Mixed-method approaches may be used to allow for a qualitative exploration of context and culture, together with a quantitative prediction. Longitudinal studies aimed at exploring causal relationships that variables (including mental disorders) potentially have with QoL are required. Specifically more research is needed on environmental and physical correlates and predictors of QoL. Clinical trials of interventions conducted with AS\&R populations that employ instruments assessing QoL as primary outcomes is required. This is a particularly worthy area of research focus in light of the fact that many people opt not to engage with treatments for mental disorders owing to the stigma that it can bring [56].

\section{Limitations of this review}

The exclusion of grey literature may have introduced a publication bias into the findings presented in the current review. However, the peer review process for journal submission was used as a form of minimal quality assurance for the studies included in the review.

Similarly, the exclusion of articles that were not written in a language spoken by the authors (English, Spanish or Dutch) may have introduced a language bias. These decisions were made due to authors' language proficiency and a lack of time to arrange translating resources. Therefore, publications on other languages should be considered an area for future research.

The samples of the included studies varied significantly with respect to country of origin, time since resettlement, year and country of study publication. However, this reflects the reality that AS\&Rs populations tend to be very diverse in terms of their personal circumstances. Furthermore, studies recruiting AS\&Rs in low- and middleincome countries were excluded given that this review aimed to support efforts to provide further evidence to guide health and social care policy that could inform the support of AS\&R in high-income countries. As the majority of the world's AS\&R live in low- and middle- income countries [1], this limitation highlights the importance of further research concerning the factors influencing AS\&Rs' QoL in low and middle-income settings. The analyses used in the studies included in the current review do not permit causal relationships to be inferred. Finally, there was heterogeneity in the measures of QoL used and this limited efforts to synthesize the findings. Consideration was also given to conducting a meta-analysis but given the large heterogeneity of available data, a metaanalysis was deemed inappropriate.

\section{Conclusion}

In summary, this review expands knowledge on the predictors and correlates of QoL in AS\&R populations. The findings highlight that there are significant physical, psychological, social and environmental predictors and correlates that affect QoL in AS\&Rs. Overall, the majority of strong positive correlations found for oQoL were $\mathrm{MH}$ related correlates. Positive $\mathrm{MH}$ is a key determinant for good integration $[57,58]$, and good integration is a determinant of good $\mathrm{MH}$ [59]. Efforts to develop and deliver interventions to support AS\&Rs need to be aware of QoL 
as an important outcome and target important determinants thereof.

\section{Appendix}

Database Search Strategy

The databases searched were Medline, PsycINFO, CINAHL, Cochrane Library, Health Technology Assessment, National Health Service Economic Evaluation, Educational Resource Index and Abstracts, BiblioMap, Scopus, Social Sciences Citation Index, Evidence Aid, DARE, Web of Science and PubMed) up to 5th of May, 2020. The Scopus database enabled searching Embase articles not indexed in the previous databases.

Search Strategy.

\begin{tabular}{|c|c|c|c|}
\hline Concept & Keywords & $\begin{array}{l}\text { Controlled } \\
\text { Vocabulary }\end{array}$ & Example database Psychinfo \\
\hline $\begin{array}{l}\text { - Asylum } \\
\text { seekers }\end{array}$ & Asylum seeker & Asylum Seeker & $\begin{array}{l}\text { - Asylum Seekers } \\
\text { OR Refugees OR } \\
\text { political asylum OR } \\
\text { political refugee }\end{array}$ \\
\hline - Refugees & Refugee & Seekers, Asylum & $\begin{array}{l}\text { - asylum N2 seek* } \\
\text { OR refuge* OR }\end{array}$ \\
\hline $\begin{array}{l}\text { - Political } \\
\text { asylum }\end{array}$ & Political asylum & Refugee & \multirow{2}{*}{$\begin{array}{l}\text { Seeker*, Asylum OR } \\
\text { political N2 asylum } \\
\text { OR political N2 refuge* }\end{array}$} \\
\hline $\begin{array}{l}\text { - Political } \\
\text { refugees }\end{array}$ & Political refugees & Stateless people & \\
\hline \multirow[t]{3}{*}{ - Adults } & \multirow[t]{3}{*}{ Adults } & Political asylum & \multirow[t]{3}{*}{ - Adult* } \\
\hline & & Political refugees & \\
\hline & & Adult & \\
\hline $\begin{array}{l}\text { - Quality of } \\
\text { Life }\end{array}$ & Wellbeing & Wellbeing & \multirow{4}{*}{$\begin{array}{l}\text { Wellbeing OR Subjective } \\
\text { wellbeing OR Psychological } \\
\text { wellbeing OR Emotional } \\
\text { wellbeing OR Quality of life } \\
\text { OR QoL OR Life quality OR } \\
\text { Health-related quality of life } \\
\text { OR Life satisfaction OR } \\
\text { Satisfaction with life }\end{array}$} \\
\hline \multirow[t]{9}{*}{-Wellbeing } & $\begin{array}{l}\text { Subjective } \\
\text { wellbeing }\end{array}$ & Subjective wellbeing & \\
\hline & $\begin{array}{l}\text { Psychological } \\
\text { wellbeing }\end{array}$ & $\begin{array}{l}\text { Psychological } \\
\text { wellbeing }\end{array}$ & \\
\hline & $\begin{array}{l}\text { Emotional } \\
\text { wellbeing }\end{array}$ & Emotional wellbeing & \\
\hline & Quality of life & Quality of life & \multirow{4}{*}{$\begin{array}{l}\text { Well N2 being OR } \\
\text { Subjective N3 well N2 } \\
\text { being OR Psychological } \\
\text { N3 well N2 being OR } \\
\text { Emotional N3 well N2 } \\
\text { being OR Quality N3 of N3 } \\
\text { life OR QoL OR Life N2 } \\
\text { quality OR Health N2 related } \\
\text { N5 quality N3 of N3 life }\end{array}$} \\
\hline & Life quality & QoL & \\
\hline & \multirow[t]{4}{*}{ Life satisfaction } & Life quality & \\
\hline & & $\begin{array}{l}\text { Health-related quality } \\
\text { of life }\end{array}$ & \\
\hline & & Life satisfaction & OR Life N3 satisfaction \\
\hline & & Satisfaction with life & \\
\hline \multirow[t]{3}{*}{$\begin{array}{l}\text { - Predictive } \\
\text { Terms }\end{array}$} & Predictor & Predictor & $\begin{array}{l}\text { - predictor OR correlation } \\
\text { OR determinant }\end{array}$ \\
\hline & Correlation & $\begin{array}{l}\text { Correlation } \\
\text { Determinant }\end{array}$ & .predict* OR correlat* \\
\hline & Determinant & & OR determin* \\
\hline
\end{tabular}

\section{Supplementary information}

Supplementary information accompanies this paper at https://doi.org/10. 1186/s13031-020-00292-y.

Additional file 1. Appendix B Positive and negative predictors of overall QoL and each of the four domains.

\section{Acknowledgements}

Not applicable.

\section{Authors' contributions}

The substantive contribution of author CB has been the conception and design of the research, conducting the literature review, carrying out the analysis and interpretation of the findings, writing the paper and doing critical revision. Author RA has contributed by peer-reviewing the methodology and revising the final manuscript. The contribution of author CD has been to support the conception of the review and providing a critical review for its intellectual content. Author SN assisted with the synthesising of the review findings and the revising of the final manuscript. Author RW has supervised the conduct of the work, including taking part in the conception of the review, peer reviewing the methodology, analysis and interpretation, revising of the final manuscript and providing critical revision of the overall review. All authors read and approved the final manuscript."

\section{Authors' information}

Dr. Ross White is the Research Director on the Doctorate of Clinical Psychology training programme and the Interim Head of Primary Care and Mental Health of the Institute of Population Health at the University of Liverpool.

Professor Christopher Dowrick is a Professor of Primary Medical Care. Additionally, he works as a General Practitioner and is a Professorial Research Fellow with the Department of General Practice in the University of Melbourne, and Chair of the Working Party for Mental Health in the World Organisation of Family Doctors.

Dr. Sarah Nevitt is a research associate in the Department of Biostatistics at the University of Liverpool.

Miss Rebekah Amos is a PhD candidate and demonstrator at the School of Psychology at the University of Liverpool.

Miss Catharina van der Boor is a PhD candidate and demonstrator at the School of Psychology at the University of Liverpool.

\section{Funding}

This work was supported by the Economic and Social Research Council [ES/ S000976/1].

\section{Availability of data and materials}

The datasets used and/or analysed during the current study are available from the corresponding author on reasonable request.

Ethics approval and consent to participate

This article does not contain any studies with human participants or animals performed by any of the authors.

\section{Consent for publication}

Not applicable.

\section{Competing interests}

The authors declare that they have no competing interests.

\section{Author details}

'Institute of Life and Human Sciences, University of Liverpool, Brownlow Hill, Liverpool L69 3BX, UK. ${ }^{2}$ Institute of Translational Medicine, University of Liverpool, Crown Street, Liverpool L69 3BX, UK. ${ }^{3}$ University of Liverpool, G.10, Ground floor, Whelan Building, Quadrangle, Brownlow Hill, Liverpool L69 3GB, UK.

Received: 29 January 2020 Accepted: 30 June 2020

Published online: 20 July 2020

\section{References}

1. United Nations High Commissioner for Refugees. Global Trends Forced Displacement in 2018. 2019. Retrieved April 27, 2020, from https://www. unhcr.org/5d08d7ee7.pdf.

2. Turrini G, Purgato M, Ballette F, Nosè M, Ostuzzi G, Barbui C. Common mental disorders in asylum seekers and refugees: umbrella review of prevalence and intervention studies. Int J Ment Heal Syst. 2017;11(1):51.

3. World Health Organization. WHOQOL Measuring Quality of Life. Geneva: World Health Organisation; 1997. 
4. WHOQOL Group. Development of the World Health Organization WHOQOL-BREF quality of life assessment. Psychol Med. 1998;28(3):551-8.

5. Charlson F, van Ommeren M, Flaxman A, Cornett J, Whiteford H, Saxena S. New WHO prevalence estimates of mental disorders in conflict settings: a systematic review and meta-analysis. Lancet. 2019;394(10194):240-8.

6. Akinyemi OO, Owoaje ET, Ige OK, Popoola OA. Comparative study of mental health and quality of life in long term refugees and host populations in Oru-ljebu, Southwest Nigeria. BMC Res Notes. 2012;5(1):394.

7. Matanov A, Giacco D, Bogic M, Ajdukovic D, Franciskovic T, Galeazzi GM, Kucukalic A, Lecic-Tosevski D, Morina N, Popovski M, Schützwohl M. Subjective quality of life in war-affected populations. BMC Public Health. 2013;13(1):624.

8. Bosqui TJ, Marshoud B. Mechanisms of change for interventions aimed at improving the wellbeing, mental health and resilience of children and adolescents affected by war and armed conflict: a systematic review of reviews. Confl Heal. 2018;12(1):15.

9. Turrini G, Purgato M, Acarturk C, Anttila M, Au T, Ballette F, Bird M, Carswell K, Churchill R, Cuijpers P, Hall J. Efficacy and acceptability of psychosocial interventions in asylum seekers and refugees: systematic review and metaanalysis. Epidemiol Psychiatr Sci. 2019;28(4):376-88.

10. Kings College London. Searching for Systematic Reviews: Advanced search Techniques. http://libguides.kcl.ac.uk/systematicreview/advanced.

11. Field AP. Meta-analysis of correlation coefficients: a Monte Carlo comparison of fixed-and random-effects methods. Psychol Methods. 2001;6(2):161.

12. Hedges LV, Olkin I. Statistical methods for meta-analysis. Academic press; 2014

13. Riley RD, Moons KG, Snell KI, Ensor J, Hooft L, Altman DG, Hayden J, Collins GS, Debray TP. A guide to systematic review and meta-analysis of prognostic factor studies. Bmj. 2019;364:k4597.

14. Cohen J. Statistical power analysis for the behavioral sciences: Routledge; 2013.

15. Downes MJ, Brennan ML, Williams HC, Dean RS. Development of a critical appraisal tool to assess the quality of cross-sectional studies (AXIS). BMJ Open. 2016;6(12):e011458.

16. Critical Appraisal Skills Programme. CASP (Cohort Study) Checklist. [online] Available at: https://casp-uk.net/wp-content/uploads/2018/01/CASP-CohortStudy-Checklist_2018.pdf. 2018. [Accessed: 17 Dec 2018].

17. Carlsson JM, Olsen DR, Kastrup M, Mortensen EL. Late mental health changes in tortured refugees in multidisciplinary treatment. J Nerv Ment Dis. 2010;198(11):824-8.

18. Carlsson JM, Mortensen EL, Kastrup M. A follow-up study of mental health and health-related quality of life in tortured refugees in multidisciplinary treatment. J Nerv Ment Dis. 2005;193(10):651-7.

19. Carlsson JM, Mortensen EL, Kastrup M. Predictors of mental health and quality of life in male tortured refugees. Nordic J Psychiatr. 2006:60(1):51-7.

20. Carlsson JM, Olsen DR, Mortensen EL, Kastrup M. Mental health and healthrelated quality of life: a 10-year follow-up of tortured refugees. J Nerv Ment Dis. 2006;194(10):725-31.

21. Correa-Velez I, Green A, Murray K, Schweitzer RD, Vromans L, Lenette C, Brough M. Social context matters: predictors of quality of life among recently arrived refugee women-at-risk living in Australia. Journal of Immigrant \& Refugee Studies; 2020. p. 1-17.

22. Correa-Velez I, Barnett AG, Gifford SM, Sackey D. Health status and use of health services among recently arrived men with refugee backgrounds: a comparative analysis of urban and regional settlement in south-East Queensland. Aust J Prim Health. 2011;17(1):66-71.

23. Georgiadou E, Schmitt GM, Erim Y. Does the separation from marital partners of Syrian refugees with a residence permit in Germany have an impact on their quality of life? J Psychosom Res. 2020;109936.

24. Ghazinour M, Richter J, Eisemann M. Quality of life among Iranian refugees resettled in Sweden. J Immigr Health. 2004;6(2):71-81.

25. Hengst SM, Smid GE, Laban CJ. The effects of traumatic and multiple loss on psychopathology, disability, and quality of life in Iraqi asylum seekers in the Netherlands. J Nerv Ment Dis. 2018;206(1):52-60,

26. Huijts I, Kleijn WC, van Emmerik AA, Noordhof A, Smith AJ. Dealing with man-made trauma: the relationship between coping style, posttraumatic stress, and quality of life in resettled, traumatized refugees in the Netherlands. J Trauma Stress. 2012;25(1):71-8.

27. Jesuthasan J, Sönmez E, Abels I, Kurmeyer C, Gutermann J, Kimbel R, Krüger A, Niklewski G, Richter K, Stangier U, Wollny A. Near-death experiences, attacks by family members, and absence of health care in their home countries affect the quality of life of refugee women in Germany: a multiregion, cross-sectional, gender-sensitive study. BMC Med. 2018;16(1):15.

28. Kinzie JD, Kinzie JM, Sedighi B, Woticha A, Mohamed H, Riley C. Prospective one-year treatment outcomes of tortured refugees: a psychiatric approach. Torture. 2012;22(1):1-10.

29. Laban CJ, Gernaat HB, Komproe IH, De Jong JT. Prevalence and predictors of health service use among Iraqi asylum seekers in the Netherlands. Soc Psychiatry Psychiatr Epidemiol. 2007;42(10):837-44.

30. Laban CJ, Komproe IH, Gernaat HB, de Jong JT. The impact of a long asylum procedure on quality of life, disability and physical health in Iraqi asylum seekers in the Netherlands. Soc Psychiatry Psychiatr Epidemiol. 2008; 43(7):507.

31. Lee CH, Min SK, Jeon WT, Kigawa M, Sugawara M. Mental health and quality of life of north Korean defectors living in Japan. Asian J Psychiatr. 2009;2(3): 95-9.

32. Leiler A, Bjärtå A, Ekdahl J, Wasteson E. Mental health and quality of life among asylum seekers and refugees living in refugee housing facilities in Sweden. Soc Psychiatry Psychiatr Epidemiol. 2019;54(5):543-51.

33. Löfvander M, Rosenblad A, Wiklund T, Bennström H, Leppert J. A casecontrol study of self-reported health, quality-of-life and general functioning among recent immigrants and age-and sex-matched Swedish-born controls. Scand J Public Health. 2014;42(8):734-42.

34. Regev S, Slonim-Nevo V. Sorrow shared is halved? War trauma experienced by others and mental health among Darfuri asylum seekers. Psychiatry Res. 2019;273:475-80.

35. Slonim-Nevo V, Regev S, Millo Y. The psycho-social conditions of asylumseekers from Darfur in Israel. Refuge. 2015;31 (2):25-38.

36. Stammel N, Knaevelsrud C, Schock K, Walther LC, Wenk-Ansohn M, Böttche M. Multidisciplinary treatment for traumatized refugees in a naturalistic setting: symptom courses and predictors. Eur J Psychotraumatology. 2017; 8(sup2):1377552.

37. Teodorescu DS, Siqveland J, Heir T, Hauff E, Wentzel-Larsen T, Lien L. Posttraumatic growth, depressive symptoms, posttraumatic stress symptoms, post-migration stressors and quality of life in multi-traumatized psychiatric outpatients with a refugee background in Norway. Health Qual Life Outcomes. 2012;10(1):84

38. Trilesnik B, Eckhoff L, Özkan I, Loos K, Penteker G, Graef-Calliess IT. Implementing a need-adapted stepped-care model for mental health of refugees: pilot data of the state-funded project "refuKey". Anxiety. 2019;85: 75-9.

39. Von Lersner U, Wiens $U$, Elbert T, Neuner F. Mental health of returnees: refugees in Germany prior to their state-sponsored repatriation. BMC Int Health Hum Rights. 2008;8(1):8.

40. World Health Organization. Field trial WHOQOL-100 February 1995: the 100 questions with response scales. World Health Organization; 1995.

41. Bech VNP. The WHO quality of life (WHOQOL) questionnaire: Danish validation study. Nordic J Psychiatr. 2001;55(4):229-35.

42. De Vries J, Van Heck GL. Quality of life and refugees. Int J Ment Health. 1994;23(3):57-75.

43. Sreedevi A, Cherkil S, Kuttikattu DS, Kamalamma L, Oldenburg B. Validation of WHOQOL-BREF in Malayalam and determinants of quality of life among people with type 2 diabetes in Kerala, India. Asia Pac J Public Health. 2016; 28(1_suppl):62S-9S.

44. Redko C, Rogers N, Bule L, Siad H, Choh A. Development and validation of the Somali WHOQOL-BREF among refugees living in the USA. Qual Life Res. 2015;24(6):1503-13.

45. Schmidt S, Mühlan H, Power M. The EUROHIS-QOL 8-item index: psychometric results of a cross-cultural field study. Eur J Public Health. 2006; 16(4):420-8.

46. Bogic M, Njoku A, Priebe S. Long-term mental health of war-refugees: a systematic literature review. BMC Int Health Hum Rights. 2015;15(1):29.

47. Valenta M, Bunar N. State assisted integration: refugee integration policies in Scandinavian welfare states: the Swedish and Norwegian experience. J Refug Stud. 2010;23(4):463-83.

48. Phillimore J, Goodson L. Problem or opportunity? Asylum seekers, refugees, employment and social exclusion in deprived urban areas. Urban Stud. 2006;43(10):1715-36.

49. Organisation for Economic Co-operation and Development. Making integration work: refugees and others in need of protection: OECD Publishing; 2016. 
50. European Council on Refugees and Exiles (ECRE) (2016) The length of asylum procedures in Europe', October, http://www.ecre.org/wp-content/ uploads/2016/10/AIDA-Brief-DurationProcedures.pdf.

51. Bloch A. Refugees' opportunities and barriers in employment and training, vol. 179. Leeds: Corporate Document Services; 2002.

52. Hainmueller J, Hangartner D, Lawrence D. When lives are put on hold: lengthy asylum processes decrease employment among refugees. Sci Adv. 2016;2(8):e1600432.

53. Warfa N, Curtis S, Watters C, Carswell K, Ingleby D, Bhui K. Migration experiences, employment status and psychological distress among Somali immigrants: a mixed-method international study. BMC Public Health. 2012; 12(1):749.

54. Bakker L, Dagevos J, Engbersen G. The importance of resources and security in the socio-economic integration of refugees. A study on the impact of length of stay in asylum accommodation and residence status on socioeconomic integration for the four largest refugee groups in the Netherlands. J Int Migr Integr. 2014;15(3):431-48.

55. Phillimore J. Refugees, acculturation strategies, stress and integration. J Soc Pol. 2011:40(3):575-93.

56. Corrigan PW, Druss BG, Perlick DA. The impact of mental illness stigma on seeking and participating in mental health care. Psychol Sci Public Interest. 2014:15(2):37-70.

57. Robila M. Refugees and social integration in Europe. United Nations Department of Economic and Social Affairs (UNDESA); 2018

58. Schick M, Zumwald A, Knöpfli B, Nickerson A, Bryant RA, Schnyder U, Müller J, Morina N. Challenging future, challenging past: the relationship of social integration and psychological impairment in traumatized refugees. Eur J Psychotraumatol. 2016;7(1):28057.

59. Haasen C, Demiralay C, Reimer J. Acculturation and mental distress among Russian and Iranian migrants in Germany. Eur Psychiatr. 2008;23:10-3.

\section{Publisher's Note}

Springer Nature remains neutral with regard to jurisdictional claims in published maps and institutional affiliations.

Ready to submit your research? Choose BMC and benefit from:

- fast, convenient online submission

- thorough peer review by experienced researchers in your field

- rapid publication on acceptance

- support for research data, including large and complex data types

- gold Open Access which fosters wider collaboration and increased citations

- maximum visibility for your research: over $100 \mathrm{M}$ website views per year

At $\mathrm{BMC}$, research is always in progress.

Learn more biomedcentral.com/submissions 